\title{
Uncertainty Avoidances among International Students towards Malay Food Acceptance
}

\author{
S. N. Amira, Z. Artinah \\ Universiti Teknologi MARA, Malaysia \\ nurulamiramohdsanip@yahoo.com
}

\begin{abstract}
Uncertainty avoidance towards certain culture and food has dominantly influence the acceptance of food choices among the international students. International students can be describes as a person or group of people who arrives in other country with a priority to pursue their higher tertiary education in a better place. Experiencing new culture, food and people has absolutely influences the level of uncertainty which then resulting the rejection of certain food in the new place. Findings has shown that the uncertainty avoidances of the students has negatively significant $\left(\beta=-.165, p<.01^{* *}\right)$ with the acceptance of Malay food which than contribute to the ability of the students to accept the Malay food.
\end{abstract}

Keywords: Uncertainty avoidances, international students, Malay food, food acceptance

\section{Introduction}

Malaysia has recorded a higher number of student's admission from various international countries throughout the year. In year 2014 itself, the number of foreign students enroll in Malaysia public and private university has been reached up to a total number of 93,000 of foreign students and it is expected to be double in year 2015 (International Consultant for Education and Fairs, 2012). It is noted that, the demand for higher learning education will be focused towards Asia and south east Asia where Reg Jordan a CEO of Newcastle's Medical School mentioning that the market in Malaysia is vast and foreign students are looking forward to enroll their study in Malaysia especially with the emergence of Malaysia EduCity Iskandar that soon will be launch in early 2015 (ICEF, 2012). Arrivals of foreign students in Malaysia have been one of a major concern of most universities. Paige (1990) mentioned that the aimed of their arrivals in others country is to seek for education betterment and for future career in their area. It is worth mentioning that with the larger number of international student's arrivals in Malaysia it is somehow influences them to felt devastated and to certain extend this negative feelings creates the feeling of culture shock due to the huge differences of cultural that they reside in.

This feeling of shocks often happens due to the factor of racial discrimination, weather and food differences, language, accommodation, separation from home, restriction of diet, weak social interaction, role and status change and a different educational system (Brown, 2007). Even though study done by Cappelini and Yen (2013) showed that immigrant slowly adapting and lowering their uncertainty towards the host country culture but in Malaysia this issue remain undisclosed. In fact by looking into the significant growth of the international students in all universities around Malaysia, it is debatable whether Malay food able to be accepted by the student's even acculturation occurs among the student and the host country. Prior research by Seo, Philips and Kim (2012) in Korea reveals that in order for the foreign resident to adapt to the foreign culture, the foreigner should be influenced by income, and this situation indirectly will contribute to the feeling of anxiety and unsure with the host country they reside in (Rogers, 1995; Gudykunst \& Nishida, 2001). Indeed, study done by Tse and Crotts (2005) also illustrate the similar result where they found out a person with high level of uncertainty avoidances will ultimately limit their selection of food choice throughout the period of living in the different country. The result shows that respondents with high uncertainty avoidances significantly reject trying any new cuisine available and it is mentioned that age and the range of culinary choice are positively correlated with the rejection of the food.

\section{Uncertainty Avoidances}

Avoidance can be translated as behavioural consequences of high levels of uncertainty and anxiety encounters associated with strangers. Avoidance behaviour normally occurs when a person preventing themselves to communicates by eluding the encounter or communication with the stranger (Duronto, Nishida \& Nakayama, 2005). Hofstede (1991) in his study described uncertainty avoidances as the degree of a member in one culture feel threatened by the uncertain or unknown circumstances and similarly House, Hanges, Javidan, Dorfman and Gupta (2004) describe uncertainty avoidance as the condition whereby the 
new members in the society seek for orderliness, consistency, structure, formalized procedures and laws to cover situations in their daily lives. This definition is closely related to Hofstede (1991) understanding of uncertainty whereby in simple words he explained uncertainty as the tolerance level between the foreigner and the new culture where they need to adapt or acculturate.

Malay Food: Malay food can be characterized by its use of varieties spices, herbs, coconut milk, shrimp paste and many other ingredients which can be found locally. Indeed, Rozin (2006) also posited that there are three components that differentiates Malay food from other ethnics like Chinese and Indians which is the uses of staple ingredients, the flavor principle (widely used of lemon grass, ginger, chillies, onion, herbs and spices) and the cooking method which comprises of sautéing, boiling technique, steaming technique and many more unique ways in preparing the food. Based on the review of literature the following hypothesis was formulated:

$\mathrm{H}$ : Uncertainty avoidances influence the acceptance of Malay food among the international students.

\section{Methodology}

Participants and Procedure: The respondents of this study comprised of international students studying in Malaysia public and private universities located in Klang Valley. The study yielded $88 \%$ of response rate or 352 usable questionnaires. A 7-items instrument used to measure the uncertainty avoidances level adapted from Jung and Kellaris (2004). All items were measured using the 7-point Likert scale and written in English and piloted prior to the actual study to ensure clarity and avoid ambiguity since most of the respondents are international students.

\section{Results}

Profile of Sample: Data in the current study were gathered using multi-stage sampling with stratified and convenience sampling being done sequentially. $73.3 \%(\mathrm{~N}=258)$ of the respondent were male while the remaining $26.7 \%(\mathrm{~N}=94)$ were female with mean age of 20 -29years.40.3\% ( $\mathrm{N}=142)$ respondents has stayed in Malaysia for 1-2 years while $37.2 \%(\mathrm{~N}=131)$ has stayed in Malaysia for 2-3 years. The remaining respondent stayed in Malaysia more than 3 years. $79 \%(\mathrm{~N}=278)$ respondent were single and only $21 \%(\mathrm{~N}=74)$ respondent married while studying in Malaysia. As illustrated in Table 1 total uncertainty avoidances can be explained as $2.7 \%$ of the variance in Malay food acceptance by the international students $\left(\mathrm{R}^{2}=2.7 \%\right.$, F Change $\left.=9.764, \mathrm{p}<.001^{* *}\right)$. The beta loading $(\beta)$ value for uncertainty avoidances on Malay food acceptance $\left(\beta=-.165, p<.01^{* *}\right)$ indicating that uncertainty avoidances are negatively influenced the international student on accepting the Malay food. Thus, hypotheses are supported with negative relationship.

Table 1: Regression Analysis for Uncertainty Avoidances factor on Malay food Acceptance

\begin{tabular}{ll}
\hline Independent Variable & Model Summary 1 \\
\hline Step 1: Model Variables & -.165 \\
Uncertainty Avoidances & \\
$\mathrm{R}^{2}$ & 0.27 \\
Adjusted R & \\
F Change & 0.24 \\
Sig. F Change & 9.764 \\
\hline
\end{tabular}

Discussion: Based on the findings presented, it was observed that, uncertainty avoidances has negative relationship in influencing the acceptance of Malay food among the international students with a significant correlation $\mathrm{R}^{2}=0.24$ and beta value, $\beta=-.165(\mathrm{p}<0.01)$. This phenomenon happens probably because of the usage of cycled menu in most of the food operators in the universities cafe during breakfast, lunch and dinner which demand the students to accept Malay food during the peak hours. In fact shorten period during breaks unable the students neither to reject nor to refuse in accepting and eating whatever menus prepared by the local operators. Thus, the constrained situation has gradually forced the students to eat and dined the food available in the cafe. Perhaps the similarity in terms of taste, texture and aroma also has indirectly attracted the students to at least try and enjoyed the food. Apart from that, result also revealed that the relationship between Malay food acceptance and international students are negative which meant that international students in Malaysia are able to accept Malay food due to the fact that most of the 
international students studying in Malaysia universities came from Asia and Middle East continent which the level of uncertainty avoidances among the people are lower comparing to the others continents such as Europe, America, Australasia and others mainly from Africa.

Probably the similarity of flavour and ingredients used in the cooking also have significantly portrayed the answered of capability to eat Malay food, although they came from various part of the world. Furthermore, consistent and constant exposure towards the varieties of Malay food during the residing period has slowly persuade the students to try and experienced the uniqueness of Malay food and indirectly lowering their uncertainty avoidance on the food. In fact, the prolonged relation to the local community also has pressured the students to accept food that's available in the local community. In fact, with limited access to the ingredients and money as a student might also contributed to the negative relationship on uncertainty avoidance resulting in accepting Malay food in a constrained condition. In addition, the population of male respondent answering the questionnaires also was high comprising about $73.3 \%$ higher than female respondent. This may influence the result of negative uncertainty avoidance towards the Malay food acceptance due to the fact that most of the male respondents are not really concerned about the food that they eat but most importantly the food that they eat can satisfy hunger, reducing time and lower in cost. It is realized that percentages of single respondents answering the questioned also could be the contributor to the low uncertainty. Probably single students preferred to buy meal rather than cooked in home and therefore contribute to the lower uncertainty avoidance towards Malay food.

Implications: Findings from this current study revealed that international students studying in Malaysia experienced low uncertainty avoidance which resulting the capability in accepting Malay food in their daily life. Although Malay food is unique in terms of flavour, taste and aroma, the students are still capable to accept Malay food due to factors of social interaction with the Malay community who is the majority population in the universities. In addition, limited time, money and accessibility also may indirectly influenced the students to lowering their level of uncertainty and demand them to accept Malay food in order to survive in Malaysia. In line with abovementioned scenario, it is a good opportunity for the government and universities to work hand in hand in promoting Malay food so that the students can be the medium of transferring information about Malay food in the respective country.

\section{Limitation and Recommendations}

Although the data gathered from the respondent are higher but it cannot be used to generalize the whole population due to the fact that most of the international students answered came from the Asia continent which comprises of 115 students. It is noted that, the similarity in terms of food taste and aroma and cooking method will undoubtedly influence the students answered resulting to the low uncertainty avoidance. In addition, the language understanding also has found to be the barrier in acquiring exact result due to the fact that most of the students are barely understand the questionnaires. Therefore, several direction for future research were identifies based on the findings gathered. It is suggested in future theorized model of validity can looked upon the demographic factors such as nationalities and age of the respondents in order to obtain clearer view on the level of uncertainty avoidance. In addition, acculturation level and assimilation of the host country should be consideration before embarking the research. Thus further study should look into this restriction and to achieve better findings and level of uncertainty avoidances.

\section{References}

Brown, L. (2007). The incident of study related to stress in international student in the initial stage of the international sojourn. Journal of Studies in International Education, 12(5), 5-28.

Cappellini, B. \& Yen, D. A. (2013). Little emperor in UK: Acculturation and food over time. Journal of Business Research, 66(8), 968-974.

Duronto, P. M., Nishida, T. \& Nakayama, S. I. (2005). Uncertainty, anxiety and avoidance in communication with strangers. International Journal of Intercultural Relations, 9(1), 55-66.

Gudykunst, W. B. \& Nishida, T. (2001). Anxiety, uncertainty and perceived effectiveness of communication across relationships and cultures. International Journal of Intercultural Relations, 22, 55-71.

House, R. J., Hanges, P. J., Javidan, M., Dorfman, P. W. \& Gupta, V. (2004). Culture, Leadership, and Organizations: The GLOBE Study of 62 Societies. London: SAGE Publications Inc.

Hofstede, G. (1991). Cultures and Organisation: Software of the Mind, Harper Collins, London. 
ICEF Monitor (2012). Malaysia aims to be the sixth largest education exporter by 2020. Retrieved from, http://monitoricef.com/2012/05/malaysia-aims-to-be-sixthlargest-education-exporter-by$2020 /$.

Jung, J. K. \& Kellaris, J. J. (2004). Cross national different in proneness to scarcity effects: the moderation roles of familiarity, uncertainty avoidance in need for cognitive closure. Journal of Psychology and Marketing, 21(9), 739-753.

Paige, M. (1990). International students cross cultural psychological perspectives. In: R. Brislin (Ed.). Applied cross-cultural psychology. Newbury Park, California: Sage.

Rozin, P. (2006). The integration of biological, social, cultural and psychological influences on food choice. The psychology of food choice. Oxford shire: CABI.

Rogers, E. M. (1995). Diffusion of Innovation. New York: The Free Press.

Seo, S., Phillip, W. M. J., Jang, J. \& Kim, K. (2012). The effect of acculturation and uncertainty avoidance on foreign resident choice for Korean foods. International Journal of Hospitality, 31(3), 631-1036.

Tse, P. \& Crotts, J. C. (2005). Antecedents of novelty seeking: international visitors' propensity to experiment across Hong Kong's culinary traditions. Tourism Management, 26(6), 965-968. 